\title{
Spectral evaluation of Earth geopotential models and an experiment on its regional improvement for geoid modelling
}

\author{
B EROL \\ Department of Geomatics Engineering, Civil Engineering Faculty, \\ Istanbul Technical University, Maslak 34469, Istanbul, Turkey. \\ e-mail: bihter@itu.edu.tr
}

\begin{abstract}
As the number of Earth geopotential models (EGM) grows with the increasing number of data collected by dedicated satellite gravity missions, CHAMP, GRACE and GOCE, measuring the differences among the models and monitoring the improvements in gravity field recovery are required. This study assesses the performance of recent EGMs derived from CHAMP, GRACE, and other data in comparison to the earlier two models in Turkish territory. Also the improvement capacities of these EGMs using local terrestrial data are inspected with two different approaches. In the first approach, the spherical harmonic coefficients of EGMs are modified depending on the local gravity data. In the second part, the original EGMs with their maximum harmonic expansions are employed in Remove Compute Restore algorithm for high resolution local geoid modelling. The assessment results with the local terrestrial data exhibited large disagreements among the models in Turkey. The outputs from regional improvements of EGMs using the gravity observations clarified the important role of the ground truth data contribution in geopotential models. The validations of the computed high resolution geoids rely on the EGMs at the GNSS/levelling networks, having 451 and 309 benchmarks, provided an absolute accuracy by means of standard deviations of the geoid height differences around $20 \mathrm{~cm}$. These results from the final stage of the case study provide a comparison among the EGMs by means of their fit to the local gravity field.
\end{abstract}

\section{Introduction}

The gravity field of the Earth shapes a unique reference system for geodetic and geophysical applications and if this field is modelled properly, the quantities (e.g., gravity acceleration, astronomical latitude and longitude on the surface of the Earth) for a point whose position is denoted by geodetic coordinates can be uniquely derived from local characteristics of the gravity field. The studies on modelling the Earth's mass distribution and its gravity potential by satellite tracking data and terrestrial gravimetry using spherical harmonic series continued since 1960's (e.g., Kaula 1966; Wenzel 1985; Rapp and Pavlis 1990; Förste et al 2005; Pavlis et al 2008; Förste et al 2009). Because additional EGMs are released into the public domain continuously and notably those including data from the dedicated satellite gravity missions, CHAMP, GRACE and GOCE, and new gravity field related datasets have been compiled over local/regional scale (see ICGEM 2010), evaluating these models to clarify the differences among them and hence to monitor the improvements

Keywords. Earth geopotential model; spectral evaluation; terrestrial data; CHAMP and GRACE; EGM08; Remove Compute Restore technique; GNSS/levelling; Turkey; data analysis; modelling. 
in the gravity field recovery are required. With this respect, a joint working group from the International Gravity Field Service (IGFS) and the International Association of Geodesy (IAG) Commission 2 was constituted for testing and validating the increasing number of EGMs.

Theoretically, observations used in the model development should be scattered to the entire earth homogenously, but it is almost impossible to realize this exactly. Hence, accuracy of gravimetric quantities computed via Earth gravity models is directly connected to the quality and global distribution of gravity data as well as to the signal power of satellite mission. Because the distribution and the availability of quality gravity data has such a major role in the EGM-derived values in different parts of the Earth, validating the models in local scale with in situ data before using them with geodetic and geophysical purposes is highly important (Gruber 2004). In this manner, Roland and Denker (2003) evaluated the fit of some of the EGMs to the gravity field in Europe using external data such as GPS/levelling and gravity anomalies, and Amos and Fearhetstone (2003) included astrogeodetic vertical deflections at the Earth surface in the external data for validating the EGMs at that date in Australia. Similar evaluations were done by Kiamehr and Sjöberg (2005), Abd-Elmotaal (2006), Rodriguez-Caderot et al (2006), Merry (2007) and Sadıq and Ahmad (2009) in Iran, Egypt, Southern Spain, Southern Africa, Pakistan, respectively. Satellite altimeter data and orbit parameters were also used by Klokočník et al (2002) and Förste et al (2009) in relative assessments of the EGMs. Erol et al (2009) and Ustun and Abbak (2010) gave some results on spectral evaluation of EGMs and their local validations using terrestrial data in the territory of Turkey. In the validation of EGMs with external data, it should be considered that the terrestrial data represent the full spectrum of the gravity signal, whereas the EGM contains only lowfrequencies. Therefore, decomposing the terrestrial data using an appropriate filtering algorithm with suitable parameters can make sense before comparing with EGM signal, at this point (e.g., Erol et al 2009).

Regional geoid determination is usually carried out by a combination of EGM and a set of observed point or mean gravity anomalies. The computations can be performed using various methods such as Remove Compute Restore (RCR) procedure as explained by Sideris (1994). Depending on the maximum degree of the applied EGM and on the regional extent of the computational area, the medium part of the gravity field spectrum is contributed from the overlapping portion of the geopotential model and the observed gravity data. Thus it should be guaranteed that both sources of information represent the same structures, this is not always true. In particular, regional studies of the geoid carried out by local agencies are often based on detailed precise gravity information which did not enter into the computation of the geopotential models (Weber and Zomorrodian 1988), which is the case for Turkey, as well. Regional geopotential model improvements based on a fitting of the global model to match the regional structures implied by the terrestrial gravity data is recommended as a solution to the problem caused by the discrepancies in regional modelling by Weber and Zomorrodian (1988), and preserving the high degree harmonic expansions without any truncation in application is told as the advantage of this procedure. However, one must be careful that the improved EGM by fitting to the local gravity field may benefit the regional geoid modelling applications, if new data (i.e., not involved in the computation of the coefficients of the original geopotential model) are available, but poorlydistributed or inaccurately-observed data may degrade the model.

In this study, in addition to external accuracy assessments of few CHAMP and GRACE only and combined EGMs (Wenzel 1985; Lemoine et al 1998; Reigber et al 2004; Tapley et al 2005; Förste et al 2005; Förste et al 2006) against GNSS/levelling and gravity anomalies similar to Erol et al (2009) and Ustun and Abbak (2010), the EGMs were also compared with the spherical harmonic expansions, which were derived by the improvement of the original geopotential models with terrestrial gravity data in and out of the computation area (Weber and Zomorrodian 1988; Kearsley and Forsberg 1990). For these comparisons, improvement of each EGM using the terrestrial gravity anomalies in the territory was done using the method by Weber and Zomorrodian (1988). This procedure leads to a harmonic expansion of non-global distributed differences between the model and the terrestrial data up to a certain degree and order. The resultant potential difference coefficients consequently were added to the original coefficients and the improved geopotential models to the regional gravity field were computed. Subsequently, in another evaluation step, the consistencies of the EGMs in a combination solution were validated. Therefore the regional high resolution geoid models were computed with Fast Fourier Transform technique (RCR method) from the terrestrial gravity data and EGMs. The final geoid models were tested against GNSS/levelling.

The spectral inspection of the global models, depending on the signal and error degree variances, allows browsing their numerical consistencies of the expected behaviour of coefficients and errors in 
the respective spectra (e.g., ICGEM 2010). However, the results from these evaluations can be told too optimistic, since they are presented as global averages and thus not necessarily representative of the performance of an EGM in particular geographic region on the Earth. Therefore local performance assessment of the models using external data spread across the territory is inevitable for providing reliable information on their performances and fit of local gravity field. Accordingly the conclusions from the numerical evaluations of the study are:

- the spectral inspections on the global qualities of the geopotential models confirmed the superiority of the models computed with contribution of data from GRACE mission,

- the external validations of the geopotential models against the ground truth data at GNSS/ levelling networks in the west of Turkey revealed large disagreements among the models in Turkey,

- the results of the regional improvement of EGMs with the terrestrial gravity data provided an idea on the improvement capacities of the models and emphasized the importance of quality and dense terrestrial data for the improvement of the models,

- the comparison of six high resolution local geoids based on each geopotential model as reference by RCR procedure at test benchmarks supplied valuable information on the performances of these global models in a hybrid solution and input for the regional gravity field modelling research as well.

\section{Data description}

\subsection{Earth geopotential models}

EGMs can be divided into three classes, namely satellite-only EGMs (derived from the tracking of artificial satellites), combined EGMs (derived from a combination of a satellite-only model, terrestrial gravimetry, satellite altimetry and/or airborne gravimetry) (see table 1) and tailored EGMs (derived by refining/fitting the existing satellite-only or combined EGMs using regional gravity data). Satellite-only EGMs are known to be weak at the coefficients of degrees higher than 60 or 70 due to several factors, such as the powerdecay of the gravitational field with altitude, modelling of atmospheric drag, non-gravitational and third-body perturbations and incomplete tracking of satellite orbits from ground stations (Rummel et al 2002). Although the effects of some of these limitations on the EGMs decreased after the dedicated satellite gravity missions CHAMP and GRACE, the new satellite-only EGMs still have not got full power until a certain degree, and rapidly increasing errors make their coefficients unreliable at high degrees. On the other hand, the combined-EGMs reduce some of the above-mentioned limitations, but errors stem from the terrestrial data will exist.

In this study, recent satellite-only and combined geopotential models from the CHAMP and GRACE missions data, released by GFZ (GeoForschungsZentrum) and the Centre for Space Research of Texas University, were tested. Table 1 summarizes the properties of these models. The two (previously released) combined models, GPM2 and EGM96, are also included in the tests, because these models are the reference models for the recently released official geoid models of Turkey (see TNFGN 2002, TNGC 2003).

The signal and error characteristics of the EGMs can be analyzed from figures $1-5$. These figures provide the degree variances of the listed models (RMS of the signal power per degree $\ell$ ) in terms of gravity anomalies (mGal) (see Roland and Denker 2003; Schwintzer 2005 for theoretical background and formulation of degree variances). These plots also include the difference anomaly degree variances of the models with EGM96 in order to provide a comparison between the new and old EGM96 that it was generally accepted as the model having the best performance among the combined EGMs until the advent of dedicated satellite gravity missions.

Table 1. The GGMs tested over Turkey (current study).

\begin{tabular}{lcll}
\hline Model & Degree & \multicolumn{1}{c}{ Data } & \multicolumn{1}{c}{ Reference } \\
\hline EGM96 & 360 & S, G, A & Limoine et al (1998) \\
GPM2 & 200 & S (LAGEOS), G, A & Wenzel (1985) \\
GGM02S & $160^{\mathrm{a}}$ & S (GRACE) & Tapley et al (2005) \\
EIGEN-CHAMP03S & $140^{\mathrm{b}}$ & S (CHAMP) & Reigber et al (2004) \\
EIGEN-CG03C & 360 & S (CHAMP, GRACE), G, A & Förste et al (2005) \\
EIGEN-GL04C & 360 & S (GRACE, LAGEOS), G, A & Förste et al (2006) \\
\hline
\end{tabular}

Note: Model coefficients are available at ICGEM (2010). Tide-free models were used.

S: satellite tracking data, G: gravity data, A: altimetry data.

a,b The coefficients complete to only $\ell=120$ are used. 


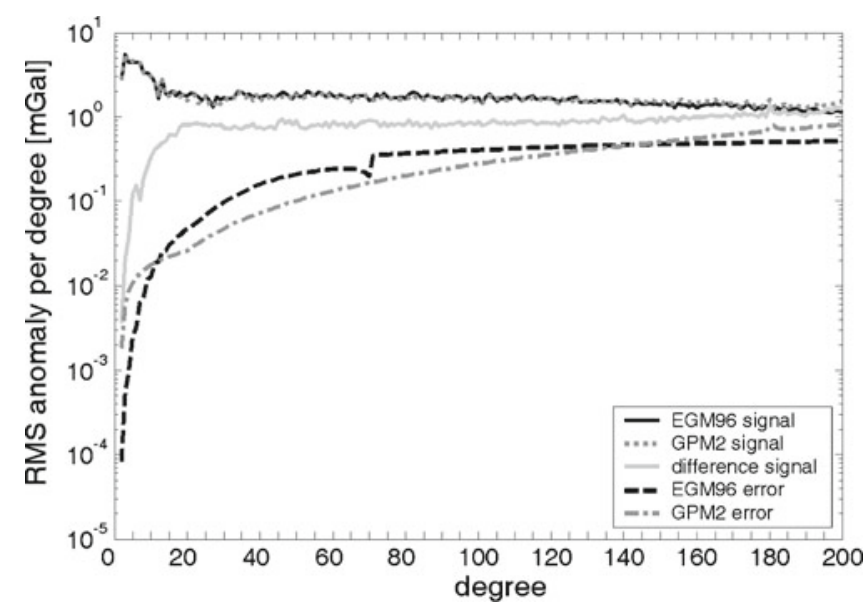

Figure 1. EGM96 vs. GPM2. Signal, error degree variances in terms of gravity anomalies for EGMs with $\ell_{\max }$ and their comparisons with EGM96.

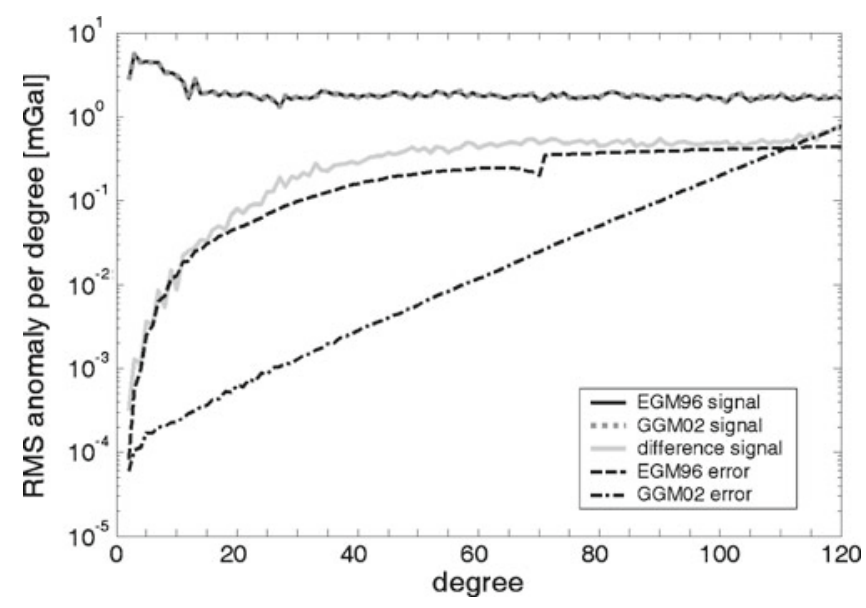

Figure 2. EGM96 vs. GGM02S. Signal, error degree variances in terms of gravity anomalies for EGMs with $\ell_{\max }$ and their comparisons with EGM96.

Correspondingly, comparison of figures 2 and 3 shows that the signal amplitudes of both satelliteonly geopotential models, GGM02S and EIGENCHAMP03S, are nearly identical up to $60^{\circ}$, however, the EIGEN-CHAMP03S model loses more power at higher degrees than GGM02S. The error estimates of EIGEN-CHAMP03S and GGM02S are also shown and compared with EGM96 in these plots. GGM02S error estimates are under the EGM96 ones up to $110^{\circ}$, while EIGEN-CHAMP03S error estimates are significantly larger than the EGM96 values above $60^{\circ}$. In figures 4 and 5 , the RMS anomaly degree variances of the combined models (complete to degree and order 360) shows that the signal powers of EGM96, EIGEN-CG03 and EIGEN-GL04 are similar until $280^{\circ}$, however EGM96 seems to lose power after that. EIGENCG03 error estimates are under both EGM96 and its successor EIGEN-GL04C.

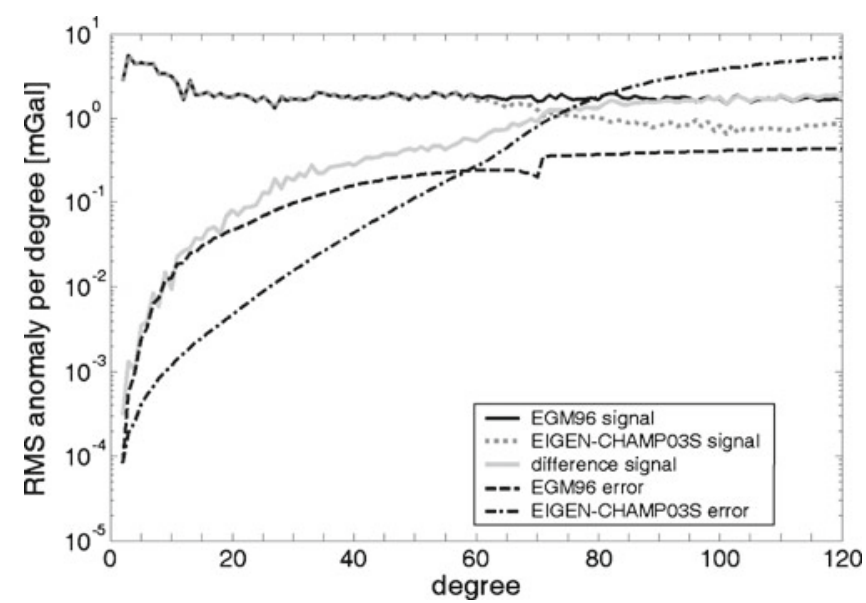

Figure 3. EGM96 vs. EIGEN-CHAMP03S. Signal, error degree variances in terms of gravity anomalies for EGMs with $\ell_{\max }$ and their comparisons with EGM96.

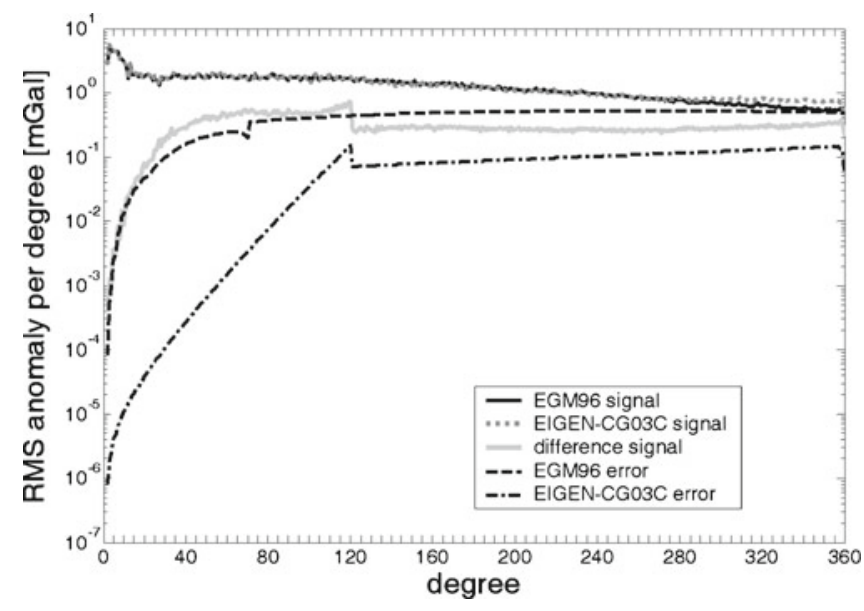

Figure 4. EGM96 vs. EIGEN-CG03C. Signal, error degree variances in terms of gravity anomalies for EGMs with $\ell_{\max }$ and their comparisons with EGM96.

The comparison of the GRACE GGM02S model and the EIGEN-CHAMP03S showed that the performance of each model in different parts of the gravity field spectrum may vary. Therefore, a weighted combination of different satellite missions data (e.g., EIGEN-CG03C is such a model, computed using a combination of data from both missions) may provide a better 'Earth geopotential model'. However, in the areas where no gravity data are available to the public (because of restricted access, data secrecy clauses, etc.) the satellite-only EGMs cannot be improved. In addition to problems in the terrestrial data (such as systematic errors in terrestrial gravity measurements), the data gaps can also affect the performance of combined EGMs in other regions as well; this is because of the solution of the boundary-value problem, where values over the entire boundary are required. Therefore, this can be a disadvantage 


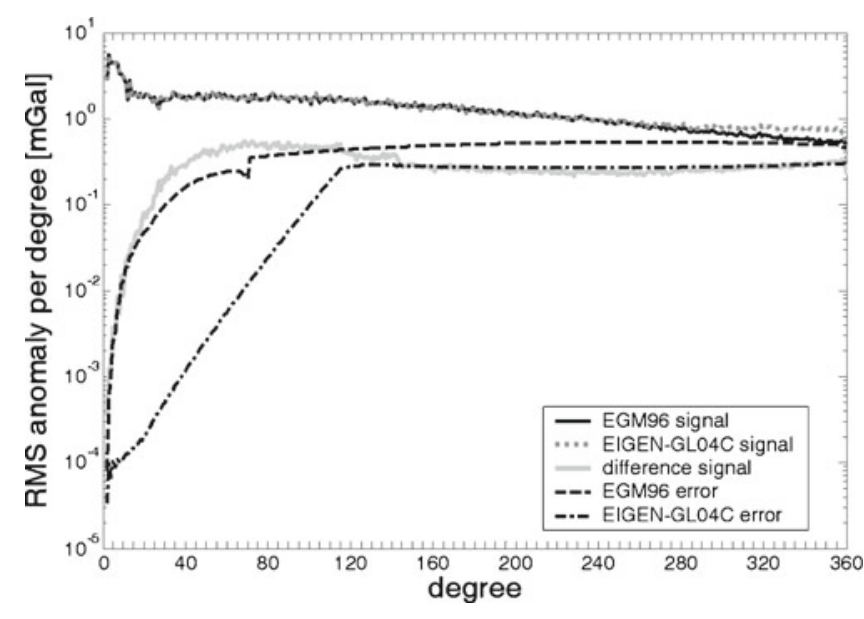

Figure 5. EGM96 vs. EIGEN-GL04C. Signal, error degree variances in terms of gravity anomalies for EGMs with $\ell_{\max }$ and their comparisons with EGM96.

when choosing a combined geopotential model as preliminary model to the regional geoid.

For details on computation strategies and performances of the tested EGMs in various territories, the references in table 1 can be considered. Regarding the GGM02S, Tapley et al (2005) recommend to use the harmonic coefficients only up to $120^{\circ}$ in applications. Therefore, GGM02S and EIGENCHAMP03S are considered up to degree and order 120 in the tests.

\subsection{Terrestrial data}

In the computation of high resolution geoid models with RCR method, the Faye gravity anomalies $\left(\Delta g_{F A}\right)$ (as an approximation of Helmert gravity anomalies) on land were restored from a complete Bouguer gravity anomaly grid $\left(\Delta g_{B}\right)$ with 5 arcmin resolution and used (cf. section 3.3). For this purpose, only the simple Bouguer anomaly term $\left(2 \pi G \rho H^{\text {grid }}\right)$ was considered $\left(\Delta g_{F A}^{\text {grid }}=\Delta g_{B}^{\text {grid }}+\right.$ $0.1119 H^{\text {grid }}$ ) and resulting Faye anomalies grid entered to the Helmert condensation approximation for the direct prediction of the geoid (Sideris and Forsberg 1991; Forsberg 1994). In practice, employing mean Faye anomalies (Helmert condensation approximation), the difficulties of computing average terrain corrections in a grid with

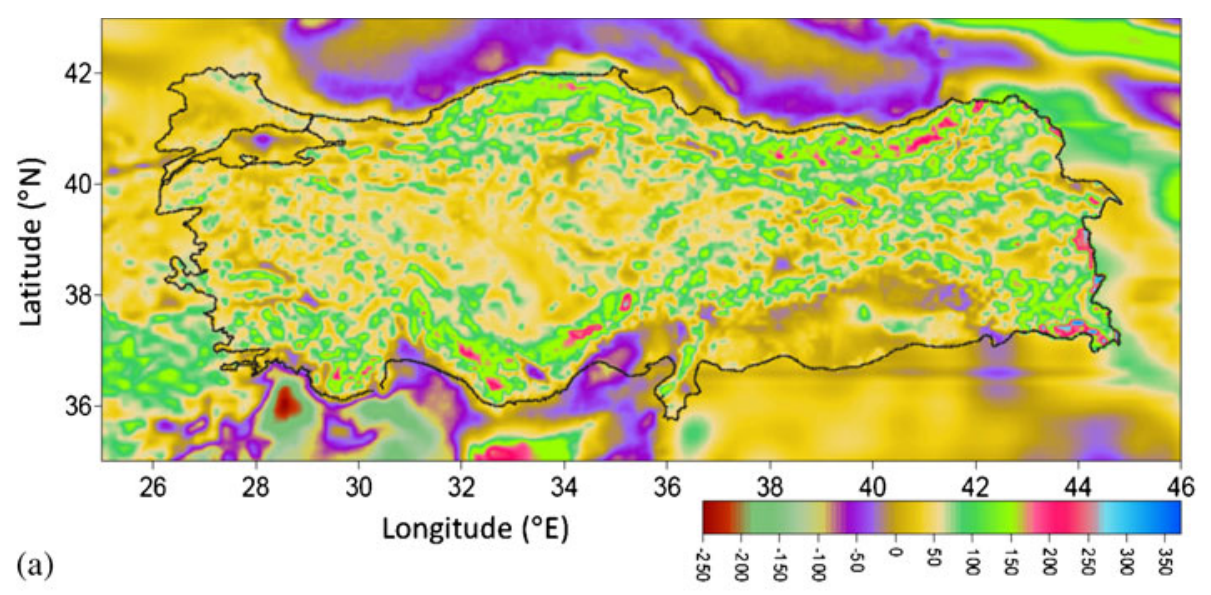

(a)

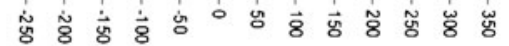

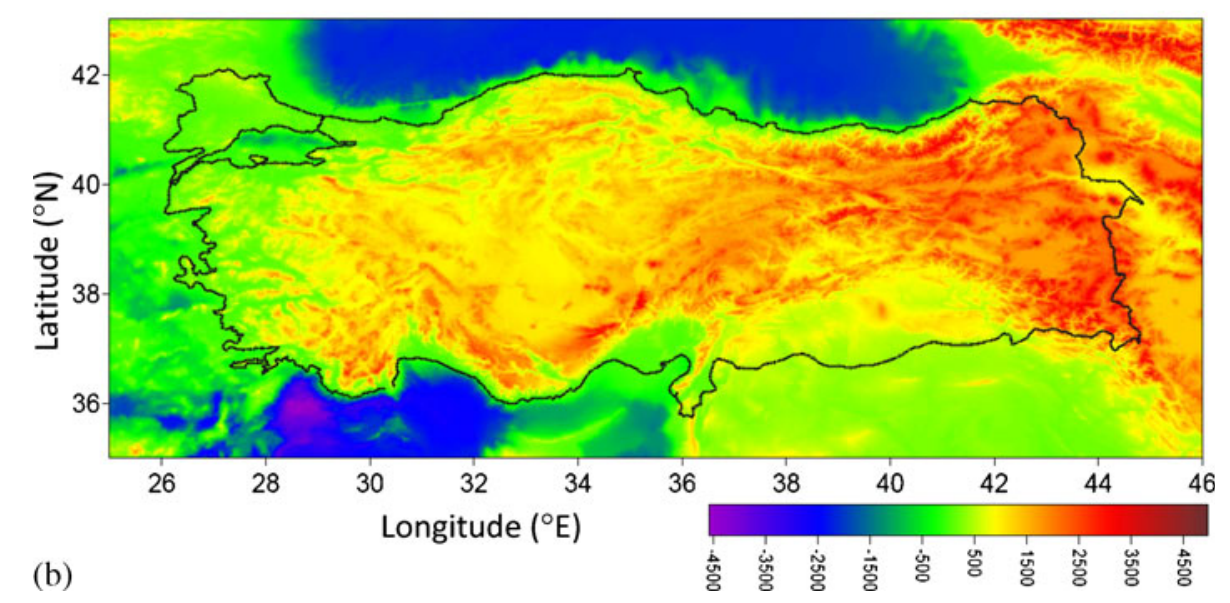

Figure 6. (a) Gravity anomalies in mGal and (b) topographic heights in meter from SRTM30 Plus by UCSD (2005). 
Table 2. Characteristics of the terrestrial data in local areas with statistics.

\begin{tabular}{lrrrr}
\hline Raw data & Min. & Max. & Mean & $\sigma$ \\
\hline Istanbul & & & & \\
$\Delta g_{\text {Free-air }[\mathrm{mGal}]}$ & -13.65 & 188.34 & 46.91 & 25.80 \\
$N_{\text {GPS/lev. }[\mathrm{m}]}$ & 35.74 & 39.33 & 36.95 & 0.47 \\
Izmir & & & & \\
$\Delta g_{\text {Free-air }}[\mathrm{mGal}]$ & -11.81 & 63.72 & 20.42 & 17.79 \\
$N_{\text {GPS } / \text { lev. }}[\mathrm{m}]$ & 37.59 & 38.73 & 38.06 & 0.16 \\
\hline
\end{tabular}

sufficient accuracy is partly avoided (Forsberg 1994). In the terrain reduction, the heights of the corresponding grid nodes, interpolated from a digital elevation model, SRTM3, were employed (USGS 2011). In the validation results of the SRTM in Turkey by Bildirici et al (2010), the errors of the heights are reported as reach-up to 10$16 \mathrm{~m}$ in mountainous areas and are $3-5 \mathrm{~m}$ in plain topographic regions. The employed Bouger gravity anomaly grid data have been generated using the point-wise data connected to the Fundamental Gravity Network of Turkey-1999 (TFGN-99) in modified Potsdam gravity datum (International Gravity Standardization Net 1971, IGSN71)
(Demir et al 2006). According to the crossvalidation check, the accuracy of the used gravity anomalies was estimated as $\pm 7 \mathrm{mGal}$. Thereafter, the restored Faye anomalies on land were merged with the gravity anomalies at sea derived from KMS2002 satellite altimetry data. The maps in figure 6 show the gravity data used in evaluations, and the topography of the region.

The EGMs were also tested against GNSS/ levelling data in two different local areas (Istanbul and Izmir geodetic networks), having dense and accurately positioned GPS/levelling benchmarks in the western part of Turkey. Separately, Istanbul network has 451 and Izmir network has

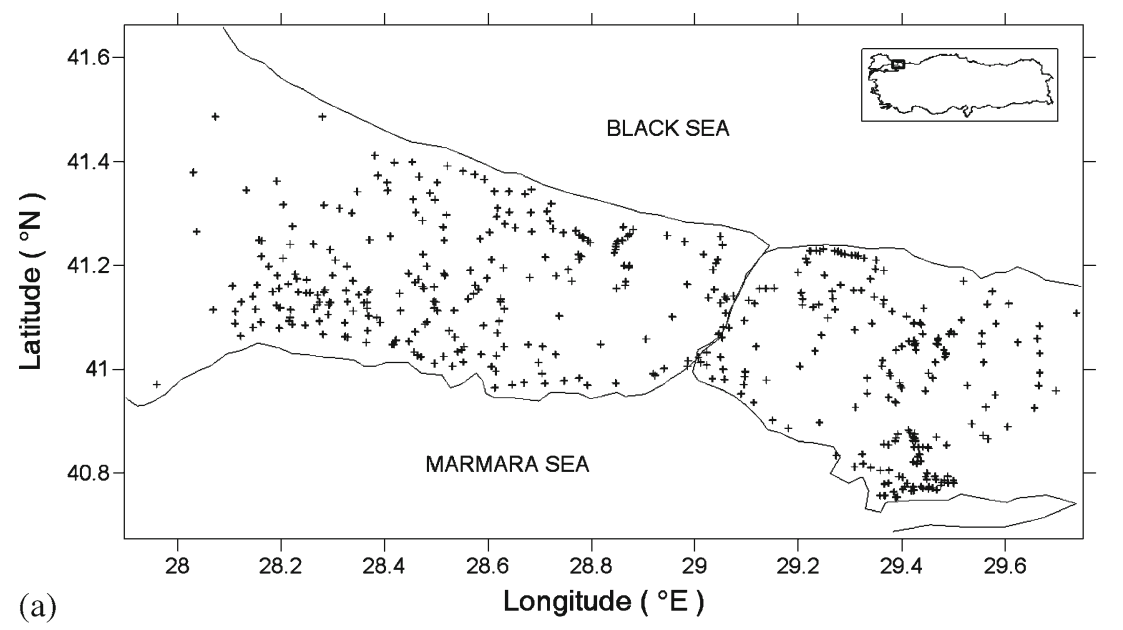

(a)

Longitude $\left({ }^{\circ} \mathrm{E}\right)$

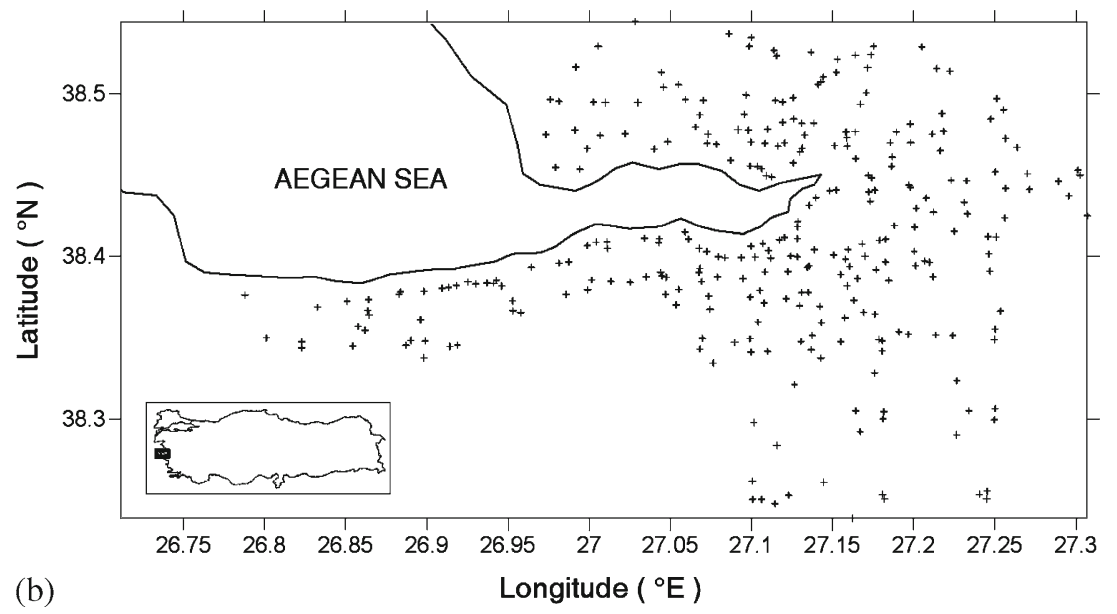

Figure 7. GPS/levelling benchmarks: (a) Istanbul and (b) Izmir. 
309 benchmarks and their Helmert orthometric heights in the Turkish National Vertical Datum (TUDKA99) are available from geometric levelling with $\pm 2.5 \mathrm{~cm}$ absolute accuracy. The GPS coordinates of the benchmarks refer to the ITRF96 datum. The accuracies are $\pm 1.8 \mathrm{~cm}$ in $2 \mathrm{D}$ coordinates and $\pm 2.0 \mathrm{~cm}$ in the ellipsoidal heights from GPS (Ayan et al 1999, 2001). Istanbul area is $65 \times 160 \mathrm{~km}^{2}$ while Izmir is $50 \times 45 \mathrm{~km}^{2}$. The approximate densities of the benchmarks can be considered as 1 benchmark per $23 \mathrm{~km}^{2}$ in Istanbul and 1 benchmark per $8 \mathrm{~km}^{2}$ in Izmir. Table 2 gives the data statistics. The distributions of GPS/levelling benchmarks are seen in figure 7 (a: Istanbul; b: Izmir networks). The topography rises to 600 and $1400 \mathrm{~m}$ from the sea level in Istanbul and Izmir, respectively.

\section{Numerical evaluation}

\subsection{Regional improvement of EGMs with local gravity data}

In the first part of the evaluations, the geopotential models were fitted to the local gravity field using terrestrial gravity anomalies and the agreements between the original EGMs and their improved spherical harmonic series (called 'terrestrially improved EGM for Turkey' (TR_EGM) in the following) were investigated using difference anomaly degree variances in terms of gravity anomalies. The method, used in the calculation of TR_EGMs, is summarized in the following (Weber and Zomorrodian 1988).

The mean gravity anomaly generated from the geopotential model is:

$$
\begin{aligned}
\Delta g_{G M} \approx & \gamma \sum_{\ell=2}^{\ell_{\max }}(\ell-1) \sum_{m=0}^{\ell} \bar{P}_{\ell m}(\cos \theta) \\
& \times\left(\bar{C}_{\ell m} \cos m \lambda+\bar{S}_{n m} \sin m \lambda\right)
\end{aligned}
$$

where $(\theta, \lambda)$ are co-latitude and longitude of the computation point, $\gamma$ is the mean gravity of the reference ellipsoid, $\bar{P}_{\ell m}$ are fully normalized Legendre functions for degree $\ell$ and order $m$, and $\bar{C}_{\ell m}$, $\bar{S}_{\ell m}$ are fully normalized geopotential coefficients of the anomalous potential, and $\ell_{\max }$ is the maximum degree of the EGM (Heiskanen and Moritz 1967).

For the regional improvement of an EGM using observed gravity anomalies, the $\Delta g_{G M}$ is compared with the observed (mean) gravity anomalies $\Delta \bar{g}$ :

$$
\delta \Delta g=\Delta \bar{g}-\Delta g_{G M}
$$

and these differences are expanded in spherical harmonics to yield corrections to the higher order (e.g., $>20$ ) potential coefficients although it seemed to have relatively small influence on the results (see Kearsley and Forsberg 1990), the modification of the lower degree terms based on local data is not recommended because of low harmonic degrees are well determined from the satellite solutions), i.e.:

$$
\begin{aligned}
\left\{\begin{array}{l}
\delta \bar{C}_{\ell m} \\
\delta \bar{S}_{\ell m}
\end{array}\right\}= & \frac{1}{4 \pi} \iint_{\sigma} \frac{R^{2}}{G M}\left(\frac{R}{a}\right)^{\ell} \frac{1}{(\ell-1) \beta_{\ell}} \delta \Delta g_{G M} \\
& \times\left\{\begin{array}{l}
\cos m \lambda \\
\sin m \lambda
\end{array}\right\} P_{\ell m}(\cos \theta) d \sigma
\end{aligned}
$$

where $R$ is the mean radius of the Earth, $a$ is semimajor axis of the reference ellipsoid, $G$ is the gravitational constant, $M$ is the mass of the Earth and $\sigma$ denotes the Earth's surface.

The coefficients of the modified model (so-called TR_EGM) are:

$$
\bar{C}_{\ell m}^{\prime}=\bar{C}_{\ell m}+\delta \bar{C}_{\ell m} ; \quad \bar{S}_{\ell m}^{\prime}=\bar{S}_{\ell m}+\delta \bar{S}_{\ell m} .
$$

These new coefficients are used in equation (1) to calculate $\Delta g_{G M}$ and from the differences in equation (2), may be formed iteratively:

$$
(\delta \Delta g)=\Delta \bar{g}-\left(\Delta g_{G M}\right)_{i} \quad i=1,2, \ldots, n .
$$

In equation (5), $i$ indicates the number of iterations in improvement procedure. Since the differences $(\delta \Delta g)$ will never be zero due to aliasing and leakage effects, and the various approximations in the method, the process may therefore be iterated until the differences no longer shows a significant decrease in the RMS variation (Weber and Zomorrodian 1988; Kearsley and Forsberg 1990). In this study, each model has improved in three iteration steps.

In order to clarify the amount of improvement and/or change of an EGM, they were compared with TR_EGMs in terms of difference degree variances. The relative evaluation of geopotential models in spectral domain provides opportunity to observe the changes of the models in different parts of the spectrum. In figure 8 , the difference degree variances in terms of gravity anomalies show that the changes of satellite-only models are bigger than the combined models and the higher degrees are affected more than the lower degrees of the spectrum. On the other hand, the difference anomaly degree variances of the combined geopotential models are consistent along the spectrum. Thereafter, the gravity anomalies calculated by the EGMs and their regionally improved versions using their coefficients until degree 120 (equation 1), were compared and results exhibited larger 


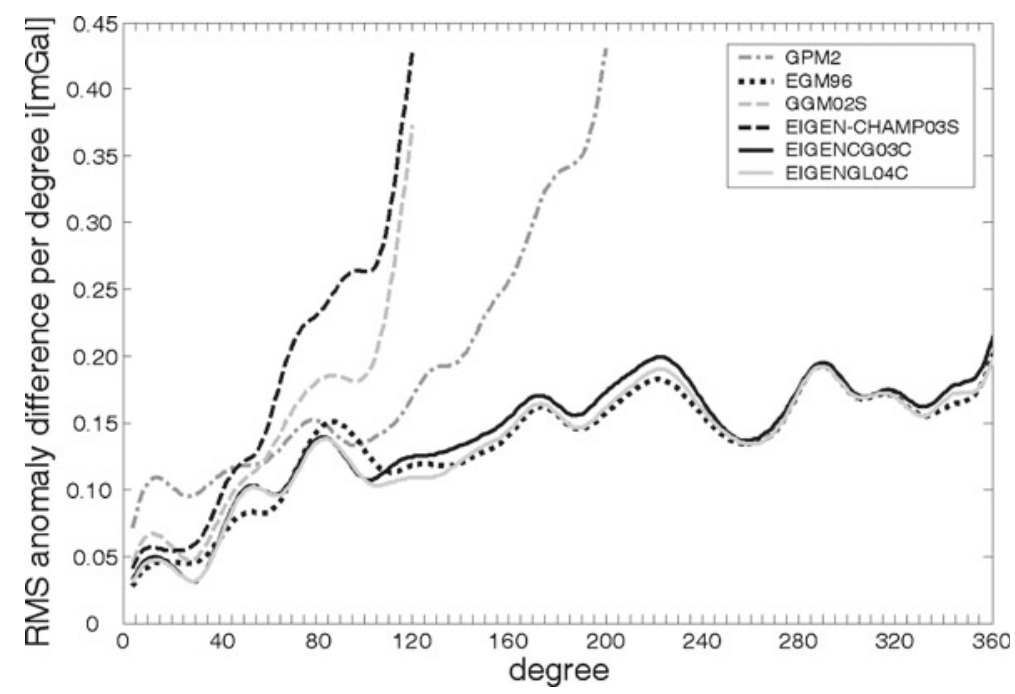

Figure 8. RMS anomaly differences per degree between the tested geopotential models and their improved versions (TR_EGMs) in Turkey.

discrepancies between the satellite-only EGMs and their modified versions, when compared with the combined ones. The basic statistics of the gravity anomaly differences are given in table 3 and the contour maps of differences with $5 \mathrm{mGal}$ were shown in figure 9 .

\subsection{Accuracy assessment of EGMs with GNSS/levelling}

The EGM derived geoid heights were compared with GNSS/levelling to provide a reliable quality measure of the EGMs specifically in the investigated region. Therefore the geoid heights $N_{G M}$ from the spherical harmonic coefficients of geopotential models to degree $\ell_{\max }$, were completed by (Heiskanen and Moritz 1967):

$$
\begin{aligned}
N_{G M} \approx & R \sum_{\ell=2}^{\ell_{\max }} \sum_{m=0}^{\ell} \bar{P}_{\ell m}(\cos \theta) \\
& \times\left(\bar{C}_{\ell m} \cos m \lambda+\bar{S}_{n m} \sin m \lambda\right) .
\end{aligned}
$$

The statistics of the geoid height differences between EGMs and the GNSS/levelling data at the benchmarks are shown in table 4. Considering the standard deviations and mean values for both local networks in the table, among the overall models, the consistency of EIGEN-CG03C to the local vertical datum is obvious. However, among the satellite-only models, it is seen that EIGENCHAMP03S fit the regional datum better than GGM02S in both test areas.

\subsection{Using EGMs in high resolution geoid modelling (RCR technique)}

In the last part of the evaluations, regional geoid models were computed using terrestrial gravity data and the geopotential models with classical RCR technique (using 1D Fast Fourier Transform). The results were evaluated against GNSS/levelling data in Istanbul and Izmir test networks.

In the RCR algorithm, the gravity anomalies are reduced for the reference field contribution and the terrain effects (see equation 7 ):

$$
\Delta g=\Delta g_{\text {Free-air }}-\Delta g_{G M}-\Delta g_{H}
$$

where $\Delta g$ is the reduced gravity anomaly, $\Delta g_{\text {Free-air }}$ is the observed (free-air) gravity anomaly and

Table 3. Statistics of gravity anomaly differences of EGMs and TR_EGMs $\left(\ell_{\max }=120\right)$ at the grid nodes with $5^{\prime}$ resolution.

\begin{tabular}{lcrcr}
\hline$\delta \Delta \mathrm{g}[\mathrm{mGal}]$ & \multicolumn{1}{c}{ Min. } & Max. & Mean & $\sigma$ \\
\hline TR_GPM2-GPM2 & -46.8 & 65.7 & 6.9 & 21.9 \\
TR_EGM96-EGM96 & -52.7 & 59.8 & 2.9 & 18.1 \\
TR_GGM02S-GGM02S & -61.2 & 80.9 & 2.2 & 21.4 \\
TR_CH03S-EIGEN CHAMP03S & -112.3 & 110.6 & 1.7 & 28.8 \\
TR_CG03C-EIGENCG03C & -51.1 & 49.6 & 2.9 & 17.2 \\
TR_GL04C-EIGENGL04C & -49.3 & 49.6 & 2.8 & 17.0 \\
\hline
\end{tabular}




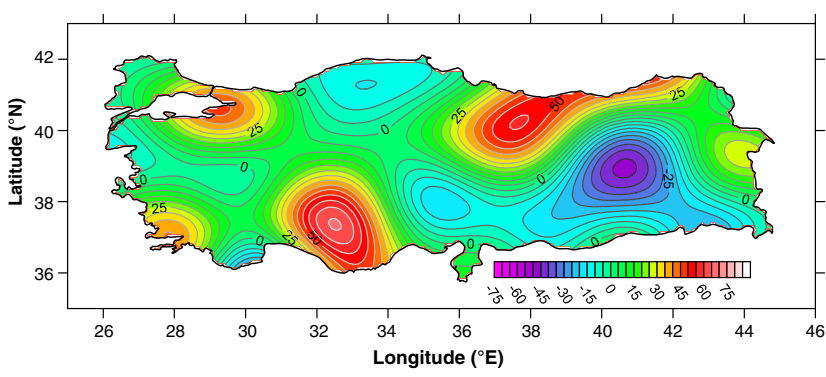

(a) $\Delta \mathrm{g}_{\mathrm{TR}} \mathrm{GPM}_{2}-\Delta \mathrm{g}_{\mathrm{GPM} 2}\left(\ell_{\max }=120\right)$

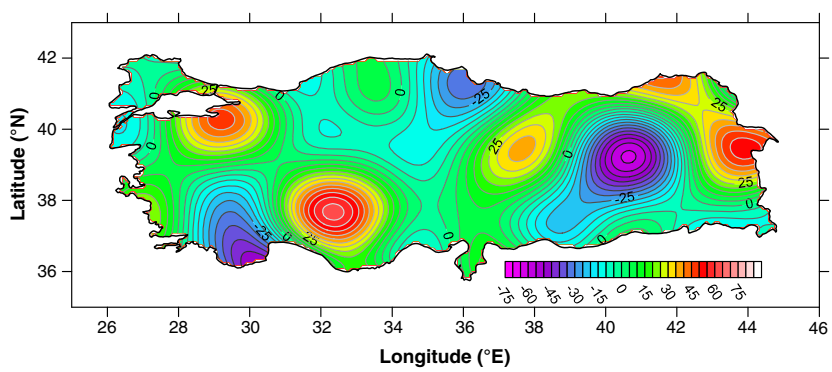

(c) $\Delta \mathrm{g}_{\mathrm{TR}}$ GGM02S $-\Delta \mathrm{g}_{\mathrm{GGM} 02 \mathrm{~S}}\left(\ell_{\max }=120\right)$

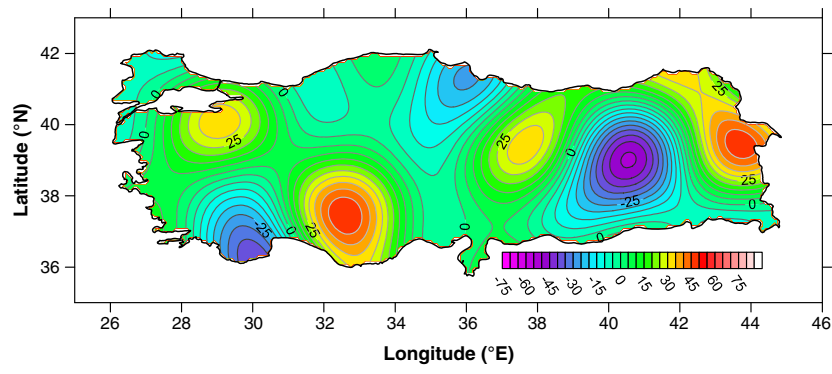

(e) $\Delta \mathrm{g}_{\mathrm{TR}} \mathrm{CG03 \textrm {C }}-\Delta \mathrm{g}_{\text {EIGENCG03C }}\left(\ell_{\max }=120\right)$

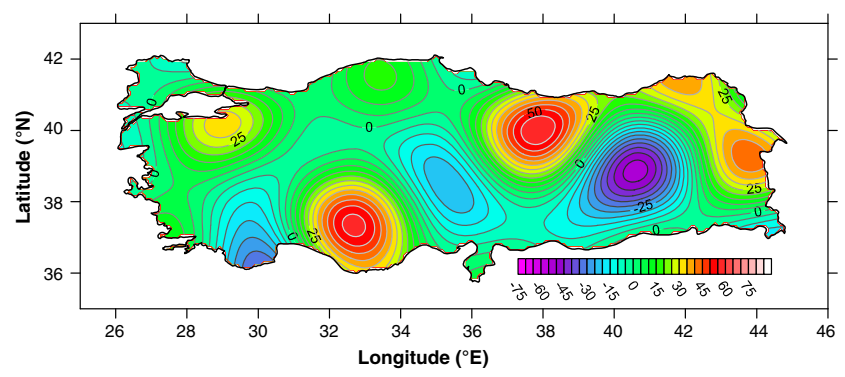

(b) $\Delta \mathrm{g}_{\text {TR_EGM }} 96-\Delta \mathrm{g}_{\text {EGM96 }}\left(\ell_{\max }=120\right)$

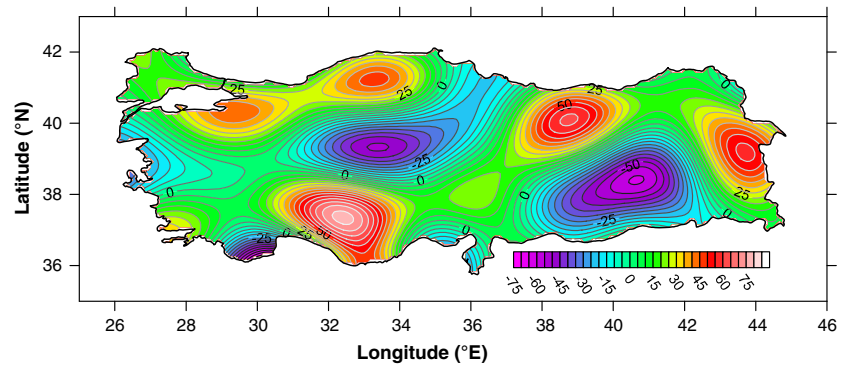

(d) $\Delta \mathrm{g}_{\text {TR_CHMP03S }}-\Delta \mathrm{g}_{\text {EIGEN CHAMP03S }}\left(\ell_{\max }=120\right)$

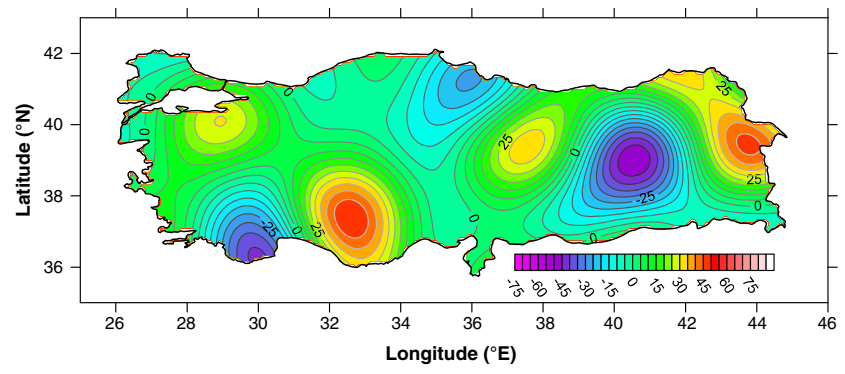

(f) $\Delta \mathrm{g}_{\mathrm{TR} \_ \text {GL04C }}-\Delta \mathrm{g}_{\text {EIGENGL04C }}\left(\ell_{\max }=120\right)$

Figure 9. Gravity anomaly differences of EGMs and TR_EGMs for $\ell_{\max }=120$ (contour interval $5 \mathrm{mGal}$ ).

Table 4. Statistics of geoid height differences between EGMs and GPS/levelling data at the benchmarks $\left(N_{G N S S / l e v .}-N_{G M}\right)$ $(\mathrm{cm})$.

\begin{tabular}{|c|c|c|c|c|c|c|c|c|c|}
\hline \multirow[b]{2}{*}{ GGM } & \multirow[b]{2}{*}{$\ell_{\text {Max }}$} & \multicolumn{4}{|c|}{ Istanbul test network (451 points) } & \multicolumn{4}{|c|}{ Izmir test network (309 points) } \\
\hline & & Min. & Max. & Mean & $\sigma_{1}$ & Min. & Max. & Mean & $\sigma_{2}$ \\
\hline GGM02S & 120 & -145.5 & 232.0 & 61.5 & 49.1 & -83.3 & 2.2 & -47.5 & 14.7 \\
\hline EIGEN-CHAMP03S & 120 & -175.1 & 172.6 & -28.7 & 35.7 & -326.0 & -207.5 & -270.9 & 22.0 \\
\hline GPM2 & 200 & 21.8 & 340.7 & 205.5 & 70.1 & 62.1 & 157.2 & 100.7 & 19.0 \\
\hline EGM96 & 360 & -191.9 & 88.5 & -94.1 & 34.4 & -206.4 & -69.3 & -144.1 & 26.1 \\
\hline EIGEN CG03C & 360 & -188.1 & 117.9 & -69.7 & 48.0 & -142.6 & -21.2 & -86.6 & 22.1 \\
\hline EIGEN GL04C & 360 & -186.7 & 149.1 & -42.2 & 57.4 & -153.1 & -18.3 & -92.6 & 25.6 \\
\hline
\end{tabular}

Table 5. Statistics of the geoid height differences $\left(N_{G N S S / l e v}-N_{\text {model }}\right)$ at the benchmarks $(\mathrm{cm})$.

\begin{tabular}{|c|c|c|c|c|c|c|c|c|c|}
\hline \multirow[b]{2}{*}{ No. } & \multirow[b]{2}{*}{ Reference } & \multicolumn{4}{|c|}{ Istanbul test network (451 points) } & \multicolumn{4}{|c|}{ Izmir test network (309 points) } \\
\hline & & Min. & Max. & Mean & $\sigma_{1}$ & Min. & Max. & Mean & $\sigma_{2}$ \\
\hline $\mathrm{I}$ & EGM GGM02S $\left(\ell_{\max }=120\right)$ & -354.4 & -45.8 & -240.9 & 24.9 & -202.4 & -121.1 & -171.5 & 13.8 \\
\hline II & EIGEN CHAMP03S $\left(\ell_{\max }=120\right)$ & -331.7 & -6.8 & -218.2 & 29.9 & -214.6 & -118.2 & -171.7 & 20.2 \\
\hline III & $\operatorname{GPM} 2\left(\ell_{\max }=200\right)$ & -231.0 & 63.2 & -119.1 & 21.6 & -73.0 & 21.6 & -32.2 & 19.9 \\
\hline IV & EGM96 $\left(\ell_{\max }=360\right)$ & -314.1 & -1.5 & -205.4 & 28.7 & -220.4 & -135.7 & -186.4 & 14.8 \\
\hline $\mathrm{V}$ & EIGEN CG03C $\left(\ell_{\max }=360\right)$ & -298.0 & -1.1 & -190.5 & 25.7 & -205.4 & -123.4 & -172.6 & 14.1 \\
\hline VI & EIGEN GL04C $\left(\ell_{\max }=360\right)$ & -314.3 & -9.8 & -205.2 & 25.4 & -202.8 & -117.8 & -168.6 & 15.1 \\
\hline
\end{tabular}


$\Delta g_{G M}$ is the EGM implied gravity anomaly (equation 1) and $\Delta g_{H}$ is the terrain effect on the gravity and derived using SRTM (Shuttle Radar Topography Mission) data with $30^{\prime \prime}$ spatial resolution. The reduced gravity anomalies provided an input to the 1D FFT evaluation of the residual geoid height, which is computed from Stokes' equation (see Haagmans et al 1993):

$$
N_{\Delta g}=\frac{R}{4 \pi \gamma} \iint_{\sigma} \Delta g S(\psi) d \sigma
$$

where $S(\psi)$ is the Stokes' kernel function with the spherical distance $\psi$ between the $P(\varphi, \lambda)$ computation point and the running point $Q(\varphi, \lambda)$ (Haagmans et al 1993; Sideris 1994).

Finally the geoid heights $N$ were restored by equation (9) and interpolated at GNSS/levelling benchmarks of the test networks.

$$
N=N_{G M}+N_{\Delta g}+N_{\text {ind }}
$$

where $N_{G M}$ is the contribution of the geopotential model (see equation 6 ), $N_{\Delta g}$ is the residual geoid height derived using equation (8) and $N_{\text {ind }}$ is the indirect effect of the terrain in the geoid heights (Sideris 1994).

In the result of the third section, six high resolution regional geoid models were computed using RCR procedure about the preliminary EGMs using each of the geopotential models at table 1, separately. These computed regional geoid models were validated against the local GNSS/levelling data $\left(N_{\text {GNSS/lev. }}\right.$ vs. $\left.N_{\text {model }}\right)$ and results of these validations are given in table 5. According to average standard deviations of geoid height differences for two local networks, the variations among the solutions are around 1-2 cm, with the exception of the solution based on EIGEN-CHAMP03S.

\section{Conclusions}

In this study, recently released CHAMP and GRACE based EGMs, classified as satellite-only and combined, in addition to two previously released models, were validated against the terrestrial data in Turkey. In this context, the external accuracy tests of EGMs at the GNSS/levelling benchmarks in the west of Turkey revealed large variations among the geopotential models that recalled the quotation from Lambeck and Coleman (1983), "the various models are not as good as they are said to be. If they were, the differences between them should not be so great as they are...". The observed land gravity data deficiency in computation of EGMs is one of the major reasons behind the relative poor fit in addition to the presence of commission and omission errors of the geopotential models (Sadiq and Ahmad 2009). The large standard deviations of residual geoid heights in the external validation of the models against GNSS/levelling data are varying between 19 and $70 \mathrm{~cm}$ (for GPM2 with $\ell_{\max }=200$ ). The coarse results may be due to the lack or poor coverage of the terrestrial data in and around the territory contributed to the EGMs. If a better coverage of terrestrial gravity data from Turkey were to be used in the calculation of the spherical harmonics of geopotential models, the long and medium wavelength of geoid features in the territory would be more improved and the models would reveal better fit to the terrestrial data in the region.

Based on the validations of the EGMs with the ground-truth data, some other remarks are:

- The geoid height differences between the EGMs and GNSS/levelling data showed the superiority of the EIGEN-CG03C in the territory.

- The direct validation of EGMs against the GNSS/ levelling data may be more realistic if only the low frequency content of the terrestrial data is employed in comparisons (e.g., Erol et al 2009). However, in this case, decomposing the data using a proper filtering algorithm and deciding the appropriate level of decomposition are critical decisions and subject to trial and error procedure. All these decisions along the data filtering procedure make the comparisons complicate and time consuming.

- The tailored geopotential models (TR_EGMs) seem to have quite differences from the original models over the entire country: the differences of the EGMs from the modified ones by means of $\Delta g_{G M}$ provide varying standard deviations between 17 and $29 \mathrm{mGal}$ and mean values between 2 and $7 \mathrm{mGal}$. Although, there are changes in geopotential models (EGM vs. TR_EGM), the anticipated improvements were not possible in derived parameters (e.g., geoid heights) from the TR_EGMs when their local validations against the ground truth data are considered. In the test results of TR_EGMs versus GNSS/levelling in Izmir network, the maximum and minimum improvements are $32 \%$ and $4 \%$ for TR_EIGEN-CHAMP03S $\left(\ell_{\max }=120\right)$ and TR_EGM96 $\left(\ell_{\max }=360\right)$, respectively, in terms of standard deviation of geoidal height differences. With this conclusion, the quality and density of the terrestrial gravity data for the improvement of the EGMs is emphasised once again.

In the final stage of evaluations, the high resolution regional geoid models by RCR procedure about a preliminary EGM were computed. Since this procedure alleviates the omission errors and 
reduces portions of the EGM commission error, from the local comparison results of high resolution geoids, more realistic output on the geopotential model assessments can be expected. With this point of view, the geoid heights from the six hybrid models were compared with the GNSS/levelling heights at the benchmarks and the basic statistics of the geoid height differences $(\Delta N)$ revealed slight changes among the solutions. In the results, the standard deviations of the $\Delta N s$ vary between 19 and $21 \mathrm{~cm}$ except the only hybrid model based on EIGEN-CHAMP03S as reference, provided a standard deviation of $25 \mathrm{~cm}$, in average of Istanbul and Izmir. The mean values of the $\Delta N s$ vary between 1 and $2 \mathrm{~m}$. Depending on these results, it can be told that the RCR algorithm capable to handle the problems stem from the spherical harmonic coefficients well in its data combination strategy and reduce their effects in resultant parameters. Thus, any of the EGMs assessed in this study can be used in the determination of regional geoid models using RCR method since the difference among the solutions can be ignored. On another hand, these differences between the regional geoid model and GNSS/levelling consist the shifts because of the datum differences, errors in observables, etc., which can be removed via fitting the geoid model to the GNSS/levelling surface (e.g., Erol et al 2008, 2009) and thus more precise (geoid like) model can be obtained especially for the applications, where a relative reference surface for vertical positioning is required.

Continuous development in satellite techniques and computation algorithms bring successive improvements in the determination of the Earth gravity field models. Hence, corresponding improvements are naturally expected for regional geoid models, as well. After CHAMP and GRACE, the launch of the GOCE satellite gravity mission attracts high expectations of the community who are interested in EGMs. The new geopotential model EGM08 to degree and order 2190 was released to geodetic community as a recent product of this progress. This ultra high resolution EGM incorporates terrestrial gravity anomalies in 5 arc-min resolution and has benefited from the latest GRACE solutions. Improved altimetryderived gravity anomalies and its implied Dynamic Ocean Topography model have also been used in EGM08 computations (Pavlis et al 2008). Due to new gravity data from more sources, EGM08 represents a significant improvement over earlier models (see IAG 2009 for the local validation results of EGM08). The published results by Kilıçoğlu et al (2009); Ustun and Abbak (2010); Erol and Erol (2011) report the performance of the model in Turkish territory and agree on its improved fit of the gravity field in Turkey, as well. According to these studies, the accuracy of EGM08 is $18 \mathrm{~cm}$ in terms of standard deviation of the geoid height residuals at GNSS/levelling benchmarks. On the other hand, Kılıçoğlu et al (2011) evaluated EGM08 in RCR algorithm for determination of Turkish Hybrid Geoid model 2009 (THG09), whose data has not been officially released yet. In the result, a $42 \%$ improvement of the new high resolution geoid versus its previous version, in terms of RMS of the geoid height residuals at GNSS/levelling benchmarks, is reported (Kılıçoğlu et al 2011). Although this model has still deficiency of quality local terrestrial data, considering the overall results from these studies, the improvement in the representation of gravity field with EGM08 in Turkish territories is obvious. Therefore, more progress in future EGMs as the new local data contribution is expected. The continuation of this study is planned on validation and comparison of EGM08 in addition to GOCE-based models using higher quality and more dense terrestrial data of Turkey.

\section{References}

Amos M J and Fearhetstone W E 2003 Comparisons of global geopotential models with terrestrial gravity field over New Zealand and Australia; Geomatics Research Australasia 78 67-84.

Abd-Elmotaal H A 2006 High-degree geopotential model tailored to Egypt; (eds) Kılıçoğlu A and Forsberg R, Gravity Field of the Earth, Map Journal 18 187-192.

Ayan T, Aksoy A, Deniz R, Arslan E, Çelik R N, Özşamlı C, Denli H H, Erol S and Erol B 1999 Istanbul GPS Triangulation Network (IGNA) Project; ITU Report No. ITU 1997/3882, Istanbul Technical University, Istanbul, Turkey, $126 \mathrm{p}$.

Ayan T, Deniz R, Çelik R N, Denli H, Özludemir T, Erol S, Erol B, Akyllmaz O and Guney C 2001 Izmir Geodetic Reference System-2001; ITU Report No. ITU 2000/ 2294, Istanbul Technical University, Istanbul, Turkey, $220 \mathrm{p}$.

Bildirici I O, Ustun A, Ulugtekin N, Selvi H Z, Abbak R A, Bugdayci I and Dogru A O 2010 Compilation of digital elevation model for Turkey in 3-arc-second resolution by using SRTM data supported with local elevation data; In: Lecture Notes in Geoinformation and Cartography - Cartography in Central and Eastern Europe (eds) Gardtner G and Ortag F (Berlin: Springer), pp. $63-76$.

Demir C, Kılıçoğlu A and Fırat O 2006 Fundamental gravity network of Turkey-1999 (TTGA99); Map Journal 136 49-63.

Erol B, Erol S and Çelik R N 2008 Height transformation using regional geoids and GPS/levelling in Turkey; Survey Review 40 2-18.

Erol B, Sideris M G and Çelik R N 2009 Comparison of global geopotential models from the CHAMP and GRACE missions for regional geoid modelling in Turkey; Stud. Geophys. Geod. 53 419-441.

Erol B and Erol S 2011 GNSS in practical determination of regional heights; In: Global navigation satellite systems: 
Signal, theory and applications (ed.) S Jin, InTech, Rijeka, Croatia, pp. 127-160, doi: 10.5772/1134.

Förste C, Flechtner F, Schmidt R, König R, Meyer U, Stubenvoll R, Rothacher M, Barthelmes F, Neumayer H, Biancale R, Bruinsma S, Lemoine J M and Loyer S 2006 A mean global gravity field model from the combination of satellite mission and altimetry/gravimetry surface dataEIGEN-GL04C; Geophys. Res. Abstr. 83462.

Förste C, Flechtner F, Schmidt R, Meyer U, Stubenvoll R, Barthelmes F, König R, Neumayer K H, Rothacher M, Reigber R, Biancale R, Bruinsma S, Lemoine J M and Raimondo J C 2005 A new high resolution global gravity field model derived from combination of GRACE and CHAMP missions and altimetry/gravimetry surface gravity data; Geophys. Res. Abstr. 74561.

Förste C, Stubenvoll R, König R, Raimondo J C, Flechtner F, Barthelmes F, Kusche J, Dahle C, Neumayer H, Biancale R, Lemoine J M and Bruinsma S 2009 Evaluation of EGM2008 by comparison with other recent global gravity field models; Newton's Bull. 4 26-37.

Forsberg R 1994 Terrain effects in geoid computations; In: Lecture Notes - International School for the Determination and Use of the Geoid, International Geoid, Service, DIIAR - Politecnico di Milano, Italy (ed.) Sanso F, pp. $273-293$.

Gruber T 2004 Validation concepts for gravity field models from new satellite missions; In: Proc. Second International GOCE Users Workshop, Bratislava, Slovakia, 11-13 Nov., http://earth.esa.int/workshops/ goce04/participants/ [8.10.2010].

Haagmans R, de Min E and van Gelderen M 1993 Fast evaluation of convolution integrals on the sphere using 1D FFT and a comparison with existing methods for Stokes' integral; Manuscr. Geod. 18(5) 227-241.

Heiskanen W A and Moritz H 1967 Physical geodesy; San Fransisco: W.H. Freeman, 364p.

IAG 2009 External Quality Evaluation Reports of EGM08, Newton's Bull. 4334.

ICGEM 2010 International Center for Global Earth Models; http://icgem.gfz-potsdam.de/ICGEM/ICGEM.html [19. $10.2010]$.

Kaula W M 1966 Theory of Satellite Geodesy; Blaisdell Publishing, 124p.

Kearsley A H W and Forsberg R 1990 Tailored geopotential models - applications and shortcomings; Manuscr. Geod. 15 151-158.

Klokočník J, Reigber C, Schwintzer P, Wagner C A and Kostelecký J 2002 Evaluation of pre-CHAMP gravity field models GRIM5-S1 and GRIM5-C1 with satellite crossover altimetry; J. Geodesy 76 189-198.

Kılıçoğlu A, Direnç A, Simav M, Lenk O, Aktuğ B and Yıldız H 2009 Evaluation of the Earth Gravitational Model 2008 in Turkey; Newton's Bull. 4 164-171.

Kılıçoğlu A, Direnç A, Yıldız H, Bölme M, Aktuğ B, Simav $\mathrm{M}$ and Lenk O 2011 Regional gravimetric quasi-geoid model and transformation surface to national height system for Turkey (THG-09); Stud. Geophys. Geod. 55 $557-578$.

Kiamehr R and Sjöberg L E 2005 Comparison of the qualities of recent global and local gravimetric geoid models in Iran; Stud. Geophys. Geod. 49 289-304.

Lambeck K and Coleman R 1983 The Earth's shape and gravity field: A report of progress from 1958 to 1982; Geophys. J. Roy. Astron. Soc. 74 25-54.

Lemoine F G, Kenyon S C, Factor J K, Trimmer R G, Pavlis N K, Chinn D S, Cox C M, Klosko S M, Luthcke S B, Torrence M H, Wang Y M, Williamson R G, Pavlis E C, Rapp R H and Olson T R 1998 The Development of the joint NASA GSFC and NIMA Geopotential
Model EGM96; Technical Paper NASA/TP-1998206861, National Aeronautics and Space Administration, Maryland, 575p.

Merry C L 2007 Evaluation of global geopotential models in determining the quasi-geoid for Southern Africa; Survey Review 39 180-192.

Pavlis N K, Holmes S A, Kenyon S C and Factor J K 2008 An earth gravitational model to degree 2160: EGM2008, presented at 2008 General Assembly of the European Geosciences Union, Vienna, Austria, http://www. massentransporte.de/fileadmin/2kolloquium_muc/2008-1008/Bosch/EGM2008.pdf [19.10.2010].

Rapp R H and Pavlis N K 1990 The development and analysis of geopotential coefficient models to spherical harmonic degree 360; J. Geophys. Res. 95 21,885-21,911.

Reigber Ch, Jochmann H, Wünsch J, Petrovic S, Schwintzer P, Barthelmes F, Neumayer K H, König R, Förste Ch, Balmino G, Biancale R, Lemoine J M, Loyer S and Perosanz F 2004 Earth gravity field and seasonal variability from CHAMP; In: Earth Observation with CHAMP - Results from Three Years in Orbit (eds) Reigber Ch, Lühr H, Schwintzer $\mathrm{P}$ and Wickert J, (Berlin: Springer), pp. 25-30.

Rodriguez-Caderot G, Lacy M C, Gil A J and Blazquez B 2006 Comparing recent geopotential models in Andalusia (Southern Spain); Studia Geophysica et Geodaetica 50 619-631.

Roland M and Denker H 2003 Evaluation of terrestrial gravity data by new global gravity field; In: Gravity and Geoid - Proc. of the third meeting of the International Gravity and Geoid Commission, Thessaloniki, Greece, August 26-30, 2002 (ed.) Tziavos I N, Ziti Publishing, pp. 256-261.

Rummel R, Balmino G, Johannessen J, Visser P and Woodworth P 2002 Dedicated gravity field missions principles and aims; J. Geodyn. 33 3-20.

Sadiq M and Ahmad Z 2009 On the selection of optimal global geopotential model for geoid modelling: A case study in Pakistan; Adv. Space Res. 44 627-639.

Schwintzer P 2005 The gravity field of the Earth: Global gravitational geopotential models; In: Lecture Notes on Global Geopotential Models in memory of Peter Schwintzer - International School for the Determination and Use of the Geoid (ed.) Sanso F; International Geoid Service, DIIAR - Politecnico di Milano, Italy, pp. 54-101.

Sideris M G 1994 Geoid Determination by FFT Techniques; In: Lecture Notes - International School for the Determination and Use of the Geoid, International Geoid Service, DIIAR - Politecnico di Milano, Italy (ed.) Sanso F, pp. 213-272.

Sideris M G and Forsberg R 1991 Review of geoid prediction methods in mountainous regions; In: Determination of the Geoid - Present and Future, IAG Symposia 106 (ed.) Rapp R H, and Sanso F (Berlin: Springer-Verlag), pp. 51-62.

Tapley B, Reis J, Bettadpur S, Chambers M, Cheng M, Condi F, Gunter B, Kang Z, Nagel P, Pastor R, Pekker T, Poole S and Wang F 2005 GGM02 - An Improved Earth gravity field model from Grace; J. Geodesy 79(8) 467-478.

TNFGN 2002 Turkish National Fundamental GPS Network1999; Map Journal (Spec. edn) 16 27-31.

TNGC 2003 Turkish National Geodesy Commission Report for the period of 1999-2003; International Union of Geodesy and Geophysics (IUGG), Sapparo, Japan, pp. 4-26, http://www.iugg.org/members/nationalreport/ turkey.pdf [19.10.2010].

UCSD 2005 Satellite Geodesy at the Scripps Institution of Oceanography, University of California website http://topex.ucsd.edu [16.05.2007]. 
USGS 2011 US Geological Survey-Earth Resources Observation and Science (EROS) Centre, Shuttle Radar Topography Mission (SRTM) website http://eros.usgs.gov/\#/Find_ Data/Products_and_Data_Available/SRTM [16.12.2011]. Ustun A and Abbak R A 2010 On global and regional spectral evaluation of global geopotential models; J. Geophys. Eng. 7 369-379, doi: 10.1088/1742-2132/7/4/003.
Weber G and Zomorrodian H 1988 Regional geopotential model improvement for the Iranian geoid determination; Bull. Geod. 62(2) 125-141.

Wenzel H G 1985 Hochauflösende Kugelfunktionsmodelle für das Gravitationspotential der Erde Wissenschaftliche Arbeiten der Fachrichtung Vermessungswesen der Universität Hannover, No 137. 